\section{Effect of Variations in Tooth Flank Form Among Teeth on Gear Vibration and an Sensory Evaluation Method Using Potential Gear Noise*}

\author{
Edzrol Niza MOHAMAD**, Masaharu KOMORI**, Shigeki MATSUMURA***, \\ Chanat RATANASUMAWONG***, Masanori YAMASHITA**, \\ Takushi NOMURA**, Haruo HOUJOH*** and Aizoh KUBO** \\ ** Department of Mechanical Engineering and Science, Kyoto University, \\ Yoshidahonmachi, Sakyo-ku, Kyoto-shi, Kyoto 606-8501, Japan \\ E-mail: komorim@me.kyoto-u.ac.jp \\ *** Precision and Intelligence Laboratory, Tokyo Institute of Technology, \\ 4259 Nagatsuta-cho, Midori-ku, Yokohama 226-8502, Japan
}

\begin{abstract}
Since variations in tooth flank form among the teeth of a gear are one of the primary causes of noise and vibration in gear systems, the effects of these variations should be analyzed. In the present paper, a simulation program is proposed in which variations in tooth flank form among the teeth of a gear are considered. The effect of different surface finish methods on gear vibration was analyzed using the developed program. The effects of periodic change of profile and helix slope deviation on the vibrational excitation were also examined. The concept of potential gear noise, which is a noise to express directly the effect of tooth flank form of gear on the gear noise, is proposed and a sensory evaluation method is also proposed to evaluate sound level, noise quality and noise uncomfortness. Sensory evaluation result shows that, even if the gears manufactured by different grinding methods have the same tooth flank form macroscopically, they make a large difference in terms of noise quality or uncomfortness because microscopically, the tooth flank form is different among grinding methods. It can be concluded that the proposed sensory evaluation method of potential gear noise could enable gear designers to experience directly the effect of tooth flank form on the noise quality.
\end{abstract}

Key words: Gear, Design, Vibration, Noise, Tooth Flank Modification, Sensory Evaluation

\section{Introduction}

Research in the field of automotive gear design is vigorous because the need to reduce gear noise is increasing. In previous years, engine noise, noise associated with the vehicle aerodynamics, and road noise have been successfully reduced. As a result, noise from transmission gears, which was previously masked by these noise sources, has become increasingly audible. Thus, it is important to consider gear noise reduction in the early stage of gear design. A number of studies using various models for analyzing gear vibration and noise have been discussed [1-4] which are aimed to minimize the noise emitted from the transmission gears.

In general, for a pair of gears under a loaded condition, the tooth flank form deviation which is resulted from the manufacturing errors or tolerances is considered as one of the main factors contributing to transmission error and consequently leads to gear noise. $\mathrm{K}$. V. Froloz et al. [5] presented a study to control the gear vibration and noise which considered the tooth deformation under loading. M. Barthod et al. [6] also studied the effect of different
*Received 20 July, 2010 (№. 10-0294) [DOI: 10.1299/jamdsm.4.1166]

Copyright $(\subset 2010$ by JSME 
gearbox configurations on the gearbox rattle phenomenon while assuming a constant value of tooth meshing stiffness. However, for example, the simulation programs used in those studies assumed that each tooth of gear has an identical tooth flank form. However, in the mass-produced gears, the slope of tooth flank forms is considerably different in each tooth and this could affect the gear vibration. In the conventional simulation method, the difference in tooth flank form among each tooth cannot be taken into consideration. Kurokawa et al. [7-8] studied the influence of gear eccentricity on the transmission error and the characteristics of noise spectrum. Although they considered the difference of tooth flank form among teeth, the analysis is unable to accommodate the tooth deflection due to load.

On the other hand, recently, there have been advances in grinding technology for the reduction of gear noise. Each gear grinding method generates the tooth flank form characteristics that are specific to each grinding method and it leads to the different characteristics of gear vibration. Thus, a method to analyze the vibration performance of ground gear is needed. However, the difference of tooth flank form among grinding methods is very small. In order to analyze ground gears, not only the macroscopic form difference but also the microscopic difference such as surface irregularities must be considered. Therefore, the analysis of the effects of grinding methods on the gear vibration is difficult. Because gear grinding is important for the reduction of gear noise, a gear performance analysis method which is capable to accommodate the tooth flank form including small surface irregularities is required. Especially, it is necessary to consider the tooth flank form measured by gear measuring instrument.

Therefore, in this research, the following items are performed as primary purpose:

(1) A novel analysis method is developed, that can consider the difference of tooth flank form among each tooth and small irregularities on the tooth flank.

(2) By using the developed program, the effect of the difference of the slope in profile and helix among each tooth on gear vibration is clarified.

(3) By using the developed analysis method, gears manufactured by 5 types of surface finish methods ( 3 types of grinding methods, honing method and shaving method) are analyzed in terms of vibrational performance, in which actual tooth flank form of each tooth measured by gear measuring instrument is considered. The difference of the effects of each surface finish method on the vibrational performance is clarified.

In this research, the effect of tooth flank form on gear noise is taken as secondary purpose. There have been many researches to explain the effects of tooth flank form on the gear vibration. However, regarding the gear noise, there are few studies on the relationship between the gear noise and the tooth flank form, although there are studies focusing on the radiated noise from the gear-box. For example, in the case of ground gears, there might be a difference in noise characteristics because of the microscopic difference in tooth flank form due to various types of grinding methods. In the early stage of design, it is thought that if gear designers are able to experience the effects of the tooth flank form in reality and understand it, it contributes to designing a better tooth flank form in terms of noise quality. Therefore, the method to experience directly the gear noise influenced by the tooth flank form is needed. In order to experience the effects of the differences of tooth flank form at the microscopic level on the noise quality, an evaluation using human hearing sense is an ideal method. For that reason, in this study, the concept of potential gear noise is proposed to provide the gear designers a possibility to directly evaluate the effects of small irregularities in tooth flank forms on the gear noise by using human hearing sense. The potential gear noise generated by the proposed simulation program is a direct expression of the gear noise caused by the effects of tooth flank form and the conventional simulation programs cannot realize this. In this report, evaluation method of noise level, noise 
characteristics and uncomfortness using potential gear noise is proposed.

The techniques presented herein contribute to the effective design of low-noise gears in early stage of gear design.

\section{Proposal of Simulation Program}

\subsection{Characteristics of the Proposed Simulation Program}

A simulation program to calculate vibrational excitation that takes into account tooth meshing with elastic deformation under load and tooth flank form deviation is proposed. In order to generate vibrational characteristics that exhibit the attributes of actual gears, minute variations in the tooth flank form among teeth must be considered in the calculation.

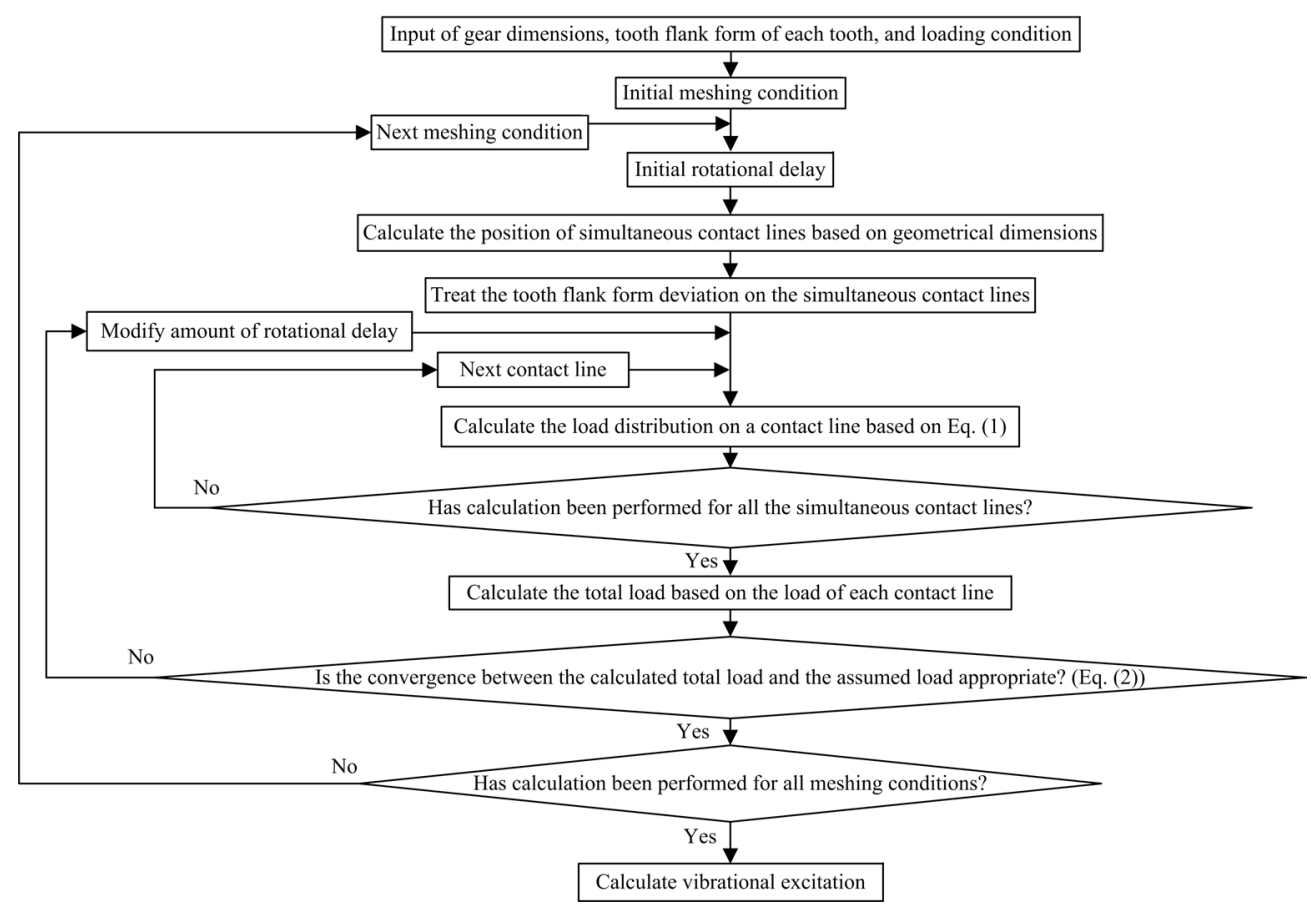

Fig. 1 Flowchart of the proposed simulation program

The fundamental algorithm of the proposed simulation program is based on a previously developed simulation program, which does not consider the variation of tooth flank form among teeth [9-11]. The load distribution on the tooth flank of an involute cylindrical gear during meshing can be obtained by solving the following equations [9]:

$$
\begin{aligned}
\int_{0}^{L(T)} K_{b}(X, \xi) p(\xi) d \xi+K_{c}(X) p(X) & =\delta_{0}(X) \\
& =\{\Delta-e(X)\} \cos \beta_{g} \\
\sum_{q} \int_{L(T)} p_{q}\left(\xi_{q}\right) d \xi_{q} \cdot \cos \beta_{g} & =W
\end{aligned}
$$

where $T$ is the rotational angular position of the gear, $L(T)$ is the length of the contact line at position $T, X$ is the coordinate of the deflection point on the contact line, $\xi$ is the coordinate of the load acting point on the contact line, $K_{b}(X, \xi)$ is a function of the influence coefficient of the bending/shearing deformation of a pair of teeth, $K_{\mathrm{c}}(X)$ is a function of the influence coefficient of the contact deformation of a pair of teeth, $p(\xi)$ is the load distribution on the contact line, $\delta_{0}(X)$ is the deformation of a pair of teeth at position $X, \Delta$ is the transmission error between the drive gear and the driven gear (displacement in the direction of line of action), $e(X)$ is the tooth flank form deviation of a pair of teeth at position $X, \beta_{\mathrm{g}}$ is the helix 
angle on the base cylinder, $q$ is a pair of teeth at the $q^{\text {th }}$ order ( $q$ means the $q^{\text {th }}$ pair of teeth in the simultaneous contacting pairs of teeth), and $W$ is the transmitted load.

Equation (1) gives the relationship among the load distribution, deformation, rotational delay, and tooth flank form deviation on a single contact line. Equation (2) gives the balance between the assumed load and the calculated total transmitted load on simultaneous contact lines. A flowchart of the proposed simulation program is shown in Fig. 1. The load distribution on the contact line is determined from Eq. (1) and Eq. (2).

If an identical tooth flank form is given to each tooth of the pinion and gear, only one combination of pinion tooth flank form and gear tooth flank form exists. Considering variations in the tooth flank form among the teeth, as shown in Fig. 2, different combinations of the tooth flank form exist, and the number of combinations is equal to the least common multiple of the tooth number $Z_{1}$ of the pinion and the tooth number $Z_{2}$ of the gear. In the proposed simulation program, all combinations of teeth are treated.

In order to consider small irregularities on tooth flank, both the number of input points expressing tooth flank form and the number of calculation divisions in progress of meshing are increased and the convergence criterion concerning Eq. (2) is set to be stricter than the conventional simulation program.

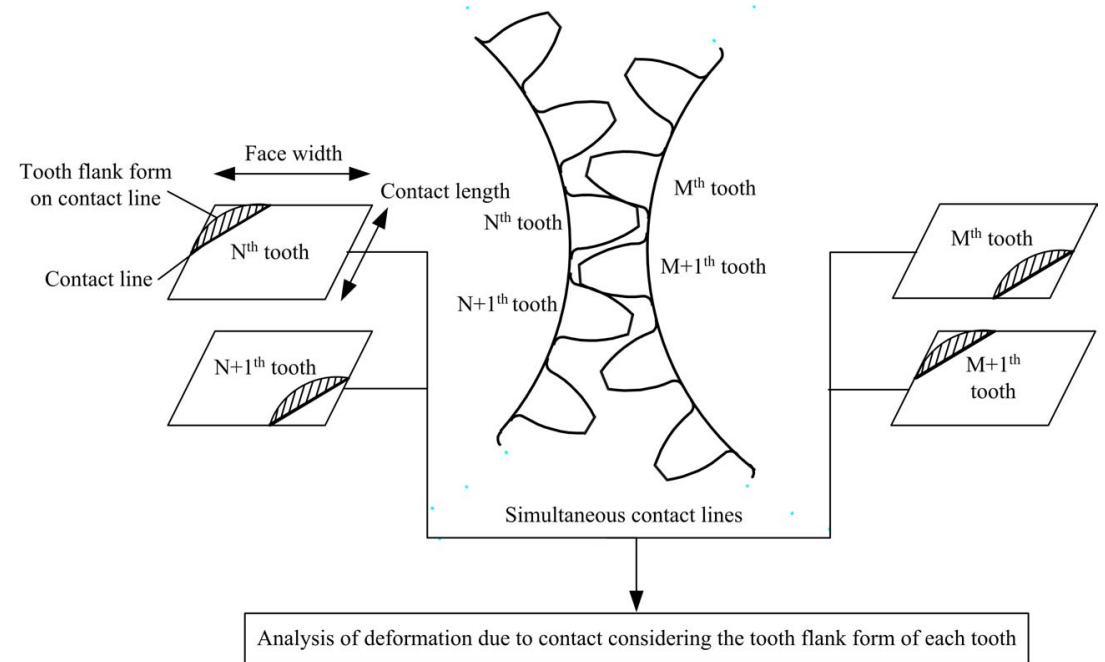

Fig. 2 Diagram showing the method to input the tooth flank form of each tooth

2.2 Analysis of the Effect of Variations in Tooth Flank Form Using the Proposed Simulation Program

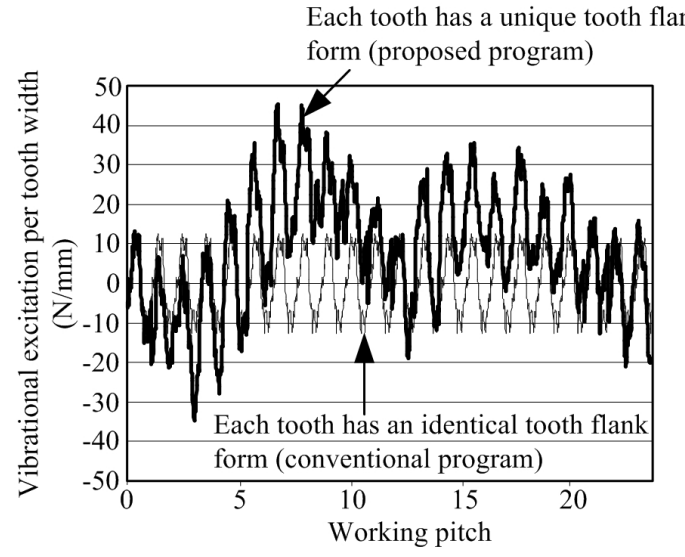

Fig. 3 Calculated vibrational excitation in which the variation of the tooth flank form among teeth is either considered (proposed program) or neglected (conventional program) 
An example of vibrational excitation calculated by the conventional simulation program and by the proposed simulation program is shown in Fig. 3. The conventional simulation indicates the repetition of an identical waveform because all of the teeth are assumed to have an identical tooth flank form. In contrast, the proposed simulation reveals detailed variations in the vibrational excitation. The FFT result of vibrational excitation is shown in Fig. 4. As shown in (a), in the analysis under the assumption of identical tooth flank form, peaks are only observed in the tooth meshing frequency component $\left(f_{z}\right)$ and its harmonics. The FFT result of vibrational excitation calculated using the proposed simulation program is shown in Fig. 4(b). Sidebands exist near the meshing component and its harmonics, and high peaks appear in the low-frequency area. These results indicate that the proposed program is capable of simulating the meshing condition of a gear with details.

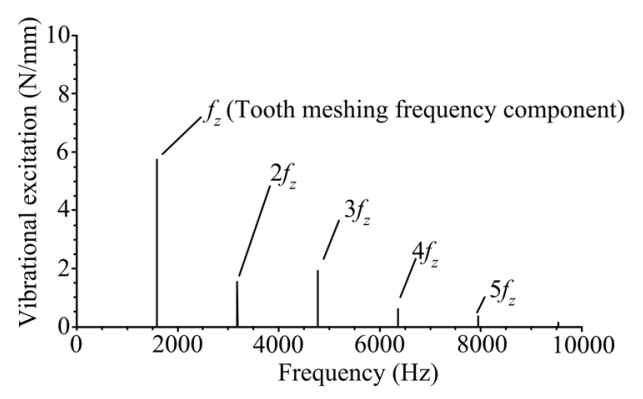

(a)

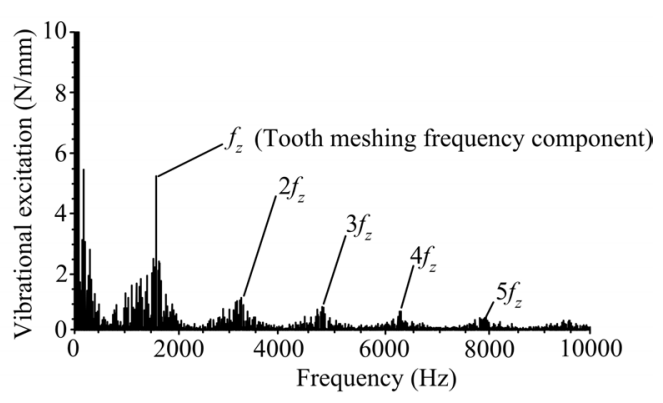

(b)

Fig. 4 FFT analysis results for vibrational excitation (a) assuming an identical tooth flank form (conventional program) and (b) unique tooth flank forms (proposed program)

\section{Effect of Surface Finish Methods on the Vibrational Excitation}

There are a number of surface finish methods for metal-based gears. Different surface finishing methods result in different tooth flank forms on the micrometer or submicrometer scale, although, the tooth flank form looks identical macroscopically. Such micrometer or submicrometer-order variations can affect the gear vibration. In the proposed simulation program, submicrometer-order variations in the tooth flank form between neighboring teeth can be considered and simulation can be performed using the actual measured tooth flank form data. In this section, the tooth flank form of gears manufactured using five different surface finish methods are measured by gear measuring instrument and are used as input data for the proposed program. Then, the proposed simulation program investigates the effect of surface finish method on the vibrational excitation under loading.

Table 1 Gear specifications

\begin{tabular}{|l|c|c|}
\hline & Drive gear & Driven gear \\
\hline Module & \multicolumn{2}{|c|}{2.5} \\
\hline Number of teeth & 30 & 53 \\
\hline Pressure angle (deg) & \multicolumn{2}{|c|}{20.0} \\
\hline Helix angle (deg) & $30.0 \mathrm{~L}$ & $30.0 \mathrm{R}$ \\
\hline Face width (mm) & \multicolumn{2}{|c|}{20.0} \\
\hline Rack shift coefficient & 0.00 & 0.121 \\
\hline Tip circle diameter(mm) & 91.6 & 158.6 \\
\hline Reference pitch diameter (mm) & 86.6 & 153.0 \\
\hline Center distance (mm) & \multicolumn{2}{|c|}{1.38} \\
\hline Transverse contact ratio & \multicolumn{2}{|c|}{0.27} \\
\hline Overlap contact ratio & 138 \\
\hline Total contact ratio & \multicolumn{2}{|c|}{245} \\
\hline Normal backlash (perpendicular to axis) & \multicolumn{2}{|c|}{} \\
\hline Torque (Nm) & \multicolumn{2}{|c|}{1.27} \\
\hline
\end{tabular}




\subsection{Surface Finish Methods}

The following surface finish methods are investigated:

1. GTM: Generating-grinding method using two grinding disks.

2. GTO: Formatting-grinding method using a tooth-groove shaped grinding stone.

3. GTR: Continuously generating-grinding method using a worm-type grinding stone.

4. THO: Continuously generating-grinding method (honing) using an internal-gear-type grinding stone.

5. SV: Shaving method before heat treatment.

The drive gears are produced by these surface finish methods, and the driven gear is finished by the GTM method. The gear specifications are shown in Table 1. The target design value of rounded profile and lead crowning modification is $5 \mu \mathrm{m}$. All gears were finished using typical manufacturing tools and machines.
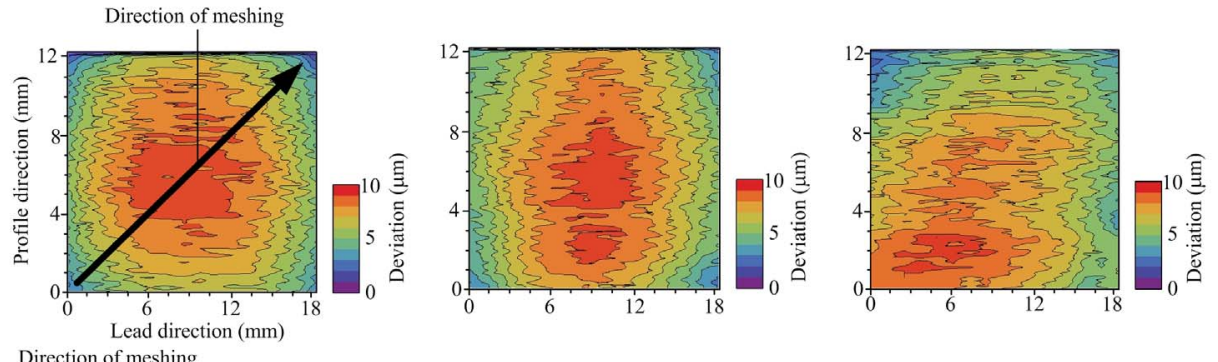

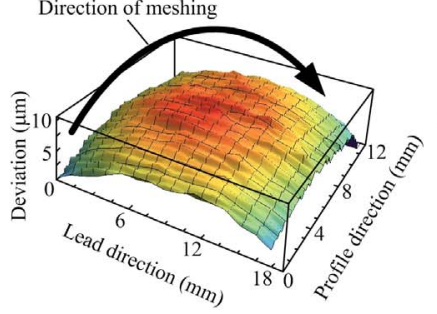

(a)
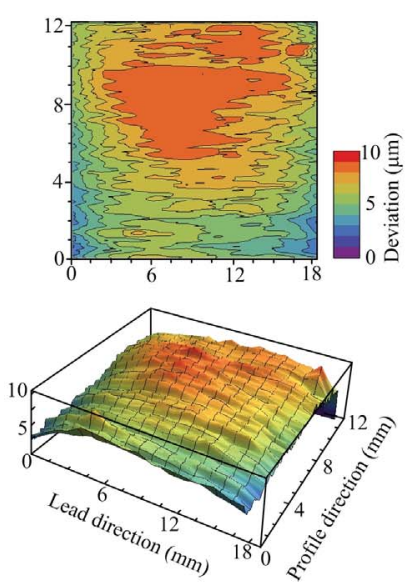

(d)

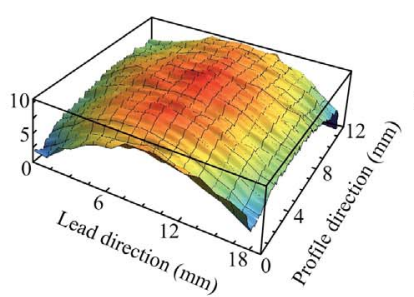

(b)
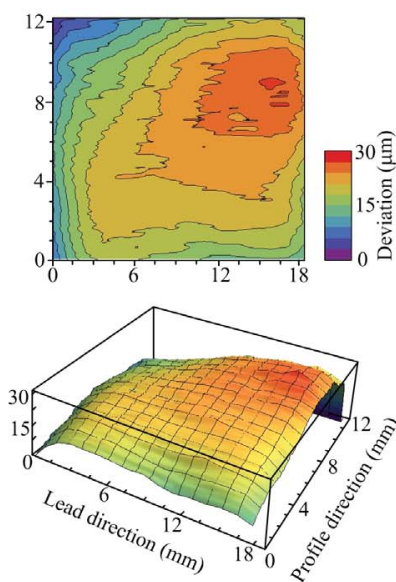

(c)

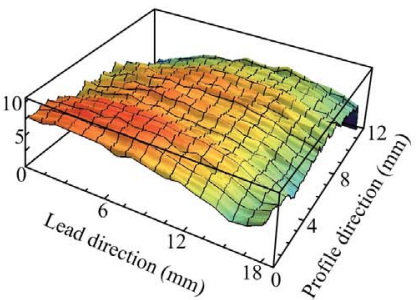

(c)
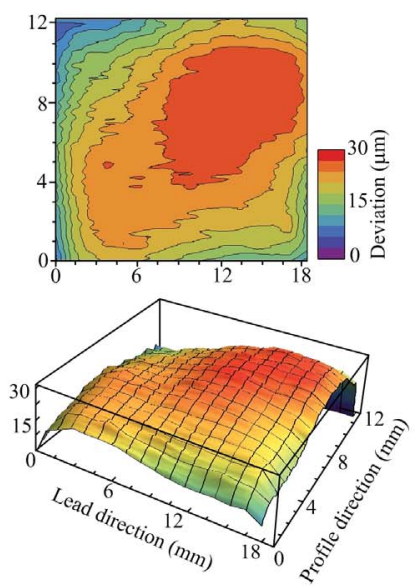

(f)

Fig. 5

Measured tooth flank forms of gears manufactured using 5 types of surface finish methods (a) GTM, (b) GTO, (c) GTR, (d) THO, (e) SV (1 ${ }^{\text {st }}$ tooth) and (f) SV ( $2^{\text {nd }}$ tooth)

The tooth flank form is precisely measured using a Hofler EMZ632. These data sets consist of 4225 input points (65 points in lead direction $\times 65$ points in tooth profile direction). The measured tooth flank forms of gears manufactured using each surface finish method are shown in Fig. 5. Note that, in Fig.5, the tooth flank form deviation is magnified when compared to the commonly used expression to make it easy to distinguish small 
differences in tooth flank form between gears. Although tooth flank form of each gear looks different because the scale of tooth flank form deviation is small in Fig.5, tooth flank form of GTM, GTO, GTR and THO gears looks similar if the scale of tooth flank form deviation is commonly used one. The rounded profile and lead crowning modifications of the manufactured gears are approximately $5 \mu \mathrm{m}$, although the SV method generated a more rounded crowning modification. The GTM and GTO methods generate a moderate bulge around the center of the tooth flank. This bulge extends diagonally in gears finished by the GTR and THO methods. The tooth flank forms of two neighboring teeth finished by SV method are shown because the characteristics of tooth flank form alternate between neighboring teeth. The reason for this is thought to be that the hob cutter is a dual threads type cutter. However, the SV method realizes the smoothest tooth flank form. There is high surface irregularity produced by the GTM, GTO, GTR, and THO methods. The tooth flank form deviation of each tooth is shown in Fig. 6. Each tooth flank form is plotted for one base pitch interval [12]. The line of contact of the tooth surface corresponds to the vertical line, and the direction of meshing is from left to right. The SV gear has large variations in tooth flank form and pitch deviation as indicated in Fig. 6. Although the GTR and GTO gears appear to produce identical tooth flank forms, the tooth flank forms have pitch deviations. The THO and GTM gears produce little variations between the teeth in terms of tooth flank form and pitch deviation.

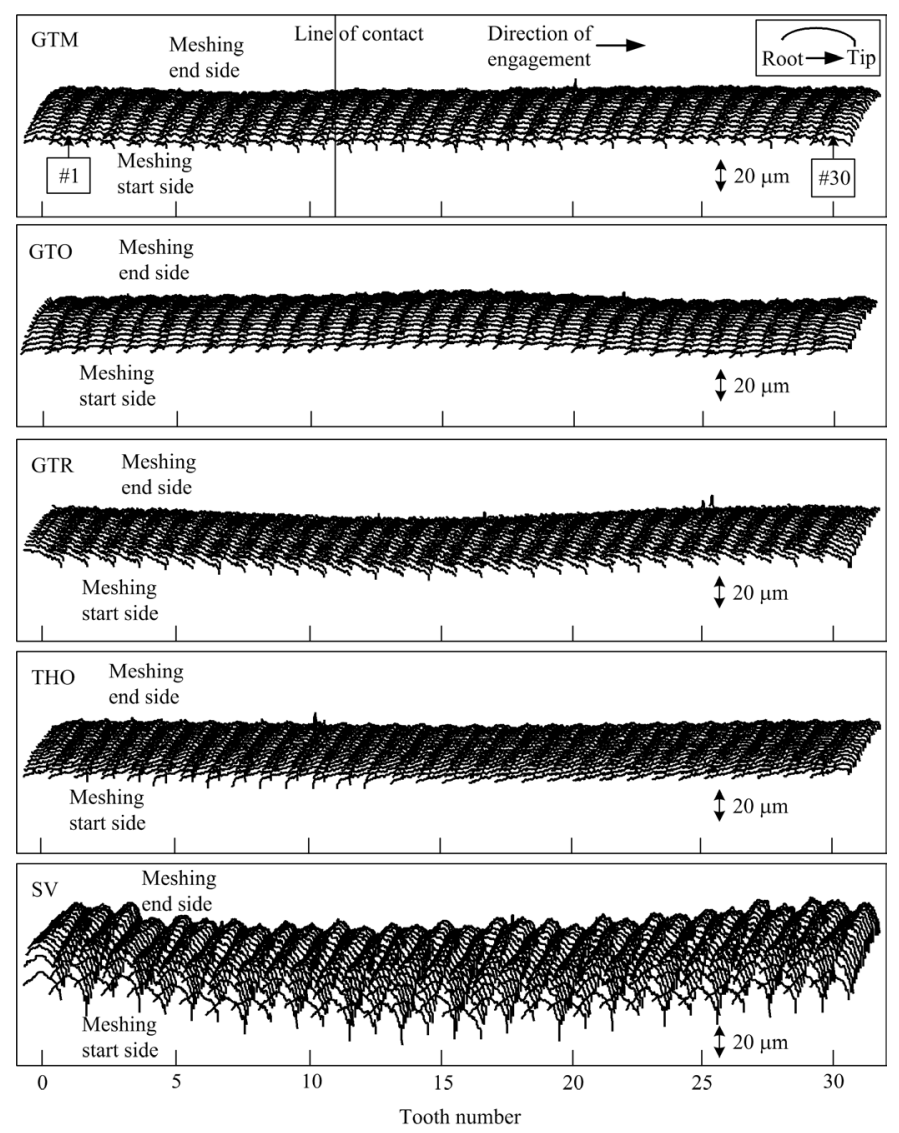

Fig. 6 Measured forms of individual teeth of gears manufactured using 5 types of surface finish methods

\subsection{Results of Simulation}

The FFT analysis results obtained by the proposed simulation program using the measured tooth flank form for each surface finish method are shown in Fig. 7. In this analysis, the rotational speed of the driven gear is $1800 \mathrm{rpm}$ (meshing frequency is 1590 $\mathrm{Hz}$ ). Although the tooth flank form of each gear appears identical on the macroscopic scale, 
the vibrational performance of each gear differs to some degree in terms of the peak of the tooth meshing frequency component $\left(f_{z}\right)$, its harmonics, and sidebands. As shown in Fig. 5, the gears finished by the GTM and GTO methods have similar tooth flank form characteristics. However, the gear finished by the GTO method has a higher peak at the tooth meshing frequency component $\left(f_{z}\right)$ than that finished by the GTM method. The gears finished by the GTM and THO methods show little variations of tooth flank form among teeth (c.f. Fig. 6). However, there are many sidebands near the meshing component and its harmonics. These results indicate that, although the macroscopic form of the tooth flank appears identical for each surface finish method, the vibrational performance for each method is different because of the existence of submicrometer-order variations in the tooth flank form. The gear finished by the SV method is found to have a non-integer meshing component $\left(0.5 f_{z}\right)$, that is caused by the alternating change of tooth flank form among neighboring teeth. These phenomena are impossible to analyze using the conventional simulation program and reveal an advantage of the proposed program whereby a more realistic operating condition can be simulated.
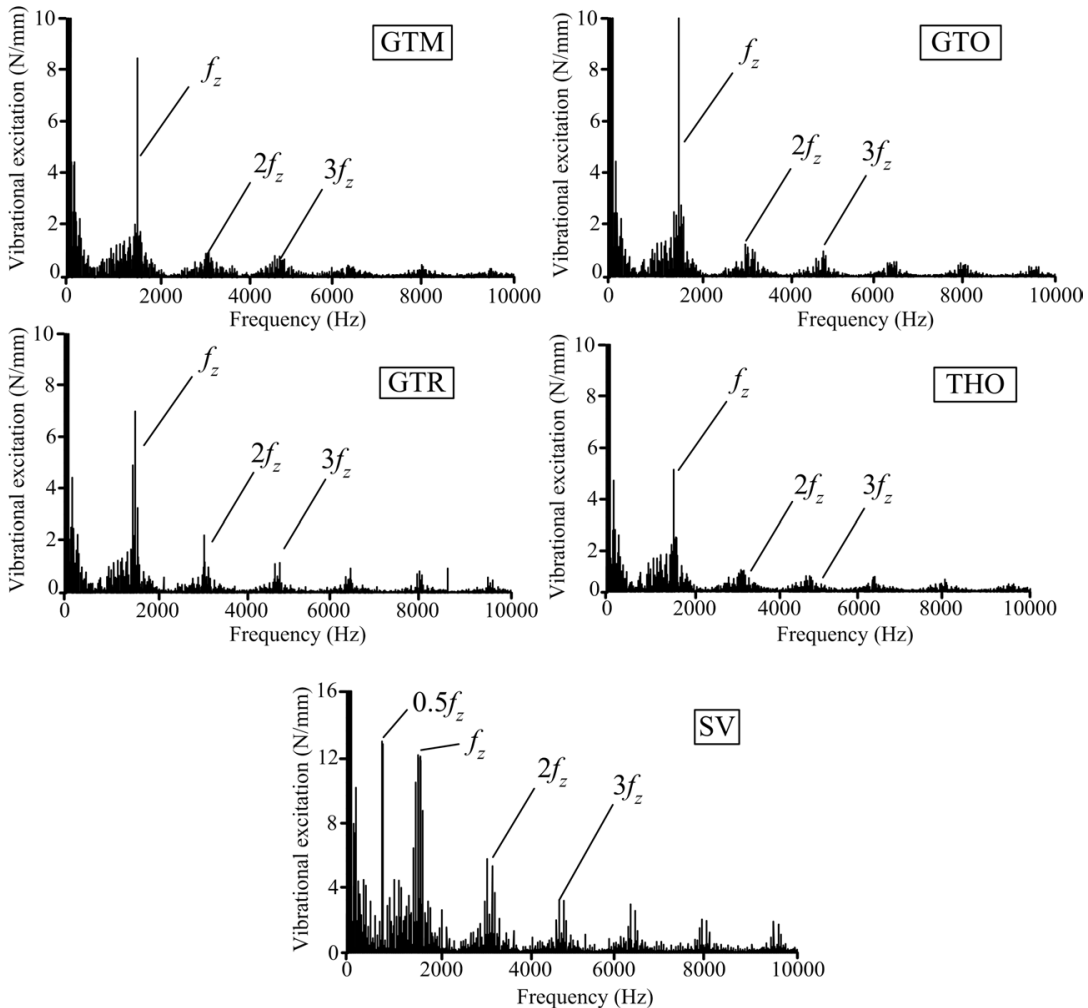

Fig. 7 FFT analysis results for the vibrational excitation of gears manufactured using 5 types of surface finish methods

\subsection{Evaluation Index for Simulated Vibrational Excitation}

In some industries, such as the automobile and heavy machinery industries, conventional simulation program of tooth contact analysis is used to evaluate and estimate the vibration quality of gears. In order to compare the quality among the designed gears, a simple evaluation index is used. For example, the amplitude of vibrational excitation or the tooth meshing component $\left(f_{z}\right)$ and its harmonics are often used as an evaluation index of vibrational excitation.

In the conventional simulation, since all teeth are assumed to have the same tooth flank form, the calculated amplitude of the vibrational excitation or the tooth meshing frequency component $\left(f_{z}\right)$ is identical for any interval of working pitch. However, due to the existence 
of manufacturing errors, each tooth has a different tooth flank form and thus, different amplitude of vibrational excitation or different meshing frequency component is caused in each working pitch. Taking these into considerations, using the conventional program, Kubo proposed an evaluation index of vibrational excitation which accommodates the difference of tooth flank form among the teeth [13]. In Kubo's method, the vibrational excitation in each working pitch is calculated from combinations of each tooth flank form of the pinion and the gear. From the obtained vibrational excitation for each working pitch, the maximum vibrational excitation is chosen as the index of vibrational excitation. Note that Kubo's method is based on the conventional simulation program and the variation in tooth flank form of neighboring teeth is not properly considered in the program, which is a different approach from the proposed simulation program in this report. Also, because Kubo's work covers only shaved gears, it is not clear whether Kubo's method is effective or not for not only shaved gear but also ground gears that can realize less gear noise. In this section, these indices are applied to the results of the proposed simulation program.

The results of evaluation using the above conventional evaluation indices are shown in Fig. 8. The tooth meshing frequency component $\left(f_{z}\right)$ of vibrational excitation for the overall working pitch is shown in Fig. 8(a), and the maximum amplitude of the vibrational excitation for each working pitch and the maximum value of its tooth meshing frequency component $\left(f_{z}\right)$ for each working pitch are shown in Fig. 8(b). In either (a) or (b), SV shows the highest index values and THO shows the lowest one. At this point, both evaluation methods show the identical result. In contrast, when comparing among GTM, GTO and GTR, GTR shows the lowest in (a) although it shows the highest in (b). In other words, 2 evaluation indices show a different tendency. These results indicate that, if there is a large difference in vibrational excitation among gears, either evaluation index shows the similar result. However, if the difference in vibrational excitation among gears is small e.g. for ground gears, 2 evaluation indices show different results. The relationship between these indices and gear noise is discussed in the next chapter.

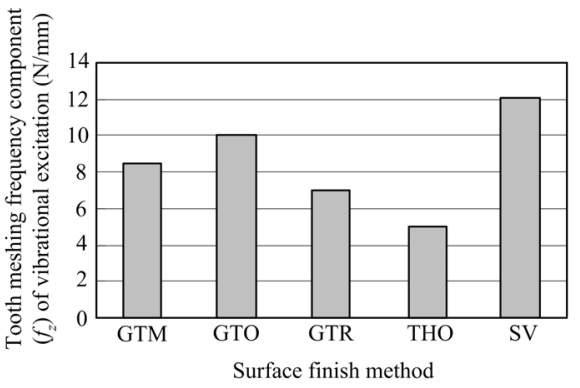

(a)

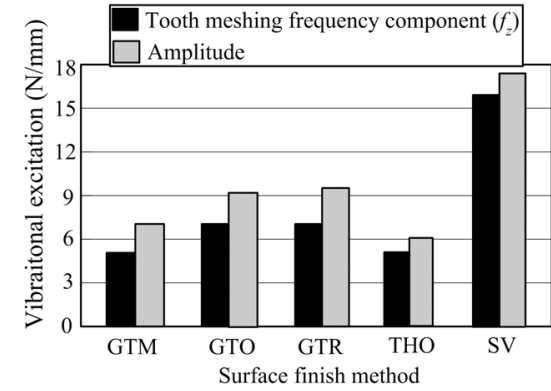

(b)

Fig. 8 Results of conventional evaluation indices applied to the proposed simulation program: (a) tooth meshing frequency component $\left(f_{z}\right)$ for the overall working pitch, (b) maximum amplitude of vibrational excitation and maximum value of tooth meshing frequency component $\left(f_{z}\right)$ for each working pitch

\section{Proposal of Potential Gear Noise and Sensory Evaluation \\ 4.1 Potential Gear Noise}

In the initial stage of gear design, if gear designers are able to experience and understand the effects of the tooth flank form on gear noise in more real, there is a possibility to design a better tooth flank form in terms of noise quality. Therefore, the method that gear designers could directly experience the gear noise caused by the tooth flank form is necessary. Gear noise is perceived by the human auditory system. Therefore, evaluation based on sound is one of the appropriate methods. In general, gear vibration is transmitted to the gearbox through shafts and bearings, and, subsequently, noise is emitted 
from the gearbox. This noise reaches the human ear, and is perceived as gear noise. If the vibration system of gears and other components are clarified, the vibration and noise of the gearbox due to gear vibration can be calculated using simulation software. However, this type of sound wave is influenced primarily by the gear shafts, bearings, and bearing housing. The assessment of gearbox noise quality might not be suitable in the design stage because there is no explicit relationship between the emitted sound and the tooth flank form of the gear.

Based on these considerations, in the present paper, potential gear noise is proposed, that is a virtual sound generated by converting the vibrational excitation waves to sound waves. The gear noise radiated from the gear-box is influenced by 2 types of influence factors which are the vibrational excitation of gear and the transmission system itself which includes shafts, bearings and gear-box structure. The potential gear noise is assumed to be affected only by the former influence factor and not the latter one. In this way, the potential gear noise has a direct relation with the tooth flank form of the gear. Therefore, this approach is considered more appropriate for analyzing the effect of the tooth flank form on the gear noise. By listening to the potential gear noise, gear designers are able to experience and understand directly the effect of the differences in tooth flank form on the magnitude and the quality of the gear noise. It does not take a long time to generate potential gear noise because it needs only the conversion process of vibrational excitation into sound. Therefore, it is possible for designers to use it frequently in the stage of trial and error.

\subsection{Sensory Evaluation Method}

Sensory evaluation method using potential gear noise is proposed here, that is composed of the following three evaluation methods.

\subsubsection{Personal Loudness Level}

In the case of evaluating the amplitude of noise, not only the subjective evaluation by the gear designers but also the objectivity and generality is required. These indicators are considered in this section. This section covers the magnitude of the noise. In the human auditory system, the perception of sound level strongly depends on the frequency of the sound. In general, sound frequencies from 2 to $4 \mathrm{kHz}$ are regarded as the most easily audible frequency range to human, and, as the frequency becomes lower, the sound becomes difficult to hear. In the present paper, a modified loudness level is proposed as an evaluation index. This modified loudness level is referred as personal loudness level herein. The personal loudness level is proposed to accommodate differences in auditory response among participants and is defined as follows:

$$
\text { Personal loudness level }[\mathrm{dB}]=20 \log P / P_{0}
$$

where $P$ is the sound pressure at $1000 \mathrm{~Hz}$ that is perceived as having the same amplitude as the object sound, and $P_{0}$ is the minimal audible sound pressure at $1000 \mathrm{~Hz}$, which is derived from the auditory characteristic of each participant.

\subsubsection{Noise Characteristics}

Even if the magnitude of gear noise is identical, there are cases where the impression of the gear noise is different. This difference can be experienced and understood by evaluating the potential gear noise using human ears. In this evaluation method, the potential gear noise is evaluated by numbers of participants and their impression are described and recorded. 


\subsubsection{Uncomfortness}

In many cases, the impression of gear noise is described using the term uncomfortable. However, the level of uncomfortable might be different among gears. In order to evaluate this, uncomfortness evaluation method is proposed. This method is performed by listening to samples of potential gear noises and ranking the gear noise in terms of its uncomfortness. To prevent the magnitude of gear noise from influencing the evaluation results, the personal loudness level of each potential gear noise is adjusted to be identical as possible.

\subsection{Sensory Evaluation of Potential Gear Noise of Gears Manufactured by Different Surface Finish Method}

Regarding the gears manufactured using different kinds of surface finish methods mentioned in Chapter 3, the potential gear noise was generated and the sensory evaluation was performed. In the experiment, the sound file is reproduced in an ear-speaker using Windows Media Player through an audio system that is connected to the driver unit. The experiment is performed in an anechoic chamber. The mean age of the 10 participants was 22 years. The impressions obtained from the participants revealed that all of the potential gear noises have similar noise characteristics as of typical gears. In other words, the potential gear noise exhibits raspy-like noise. This indicates that the potential gear noise generated by the proposed simulation program has noise characteristics similar to an actual gear noise. As shown in Fig. 3, in the conventional simulation, waveforms of identical shape are repeated in cycles. Although the sound was generated from the vibrational excitation using the conventional simulation program, the participants reported that the sound characteristics were similar to an electronic beeping sound and do not sounds like a gear noise in real world. This shows that the sound-based evaluation has become possible by the proposed simulation program, which is impossible by using conventional simulation program.

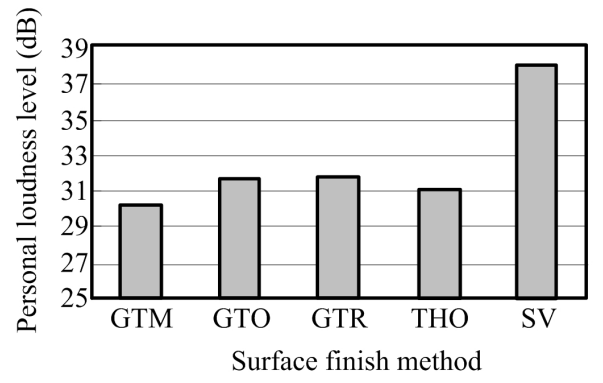

(a)

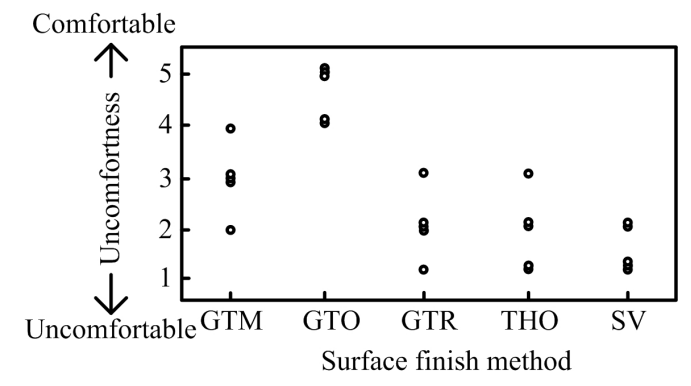

(b)

Fig. 9 (a) Results of personal loudness level of gears manufactured using various surface finish methods and (b) uncomfortness evaluation result

The personal loudness level of potential gear noise from each type of manufactured gears is obtained and shown in Fig. 9(a). SV shows the highest value and the other 4 types of gears show relatively small values. Apart from SV, within the 4 types of gears, GTO and GTR show large value whereas GTM and THO show relatively small. Therefore, this result does not conform to the result shown in Fig. 8(a). However, the result shown in Fig. 8(b) indicates a correlation tendency with the result shown in Fig. 9(a). This result indicates that using the tooth meshing frequency component $\left(f_{z}\right)$ for the overall working pitch as an index might not be appropriate for the proposed simulation program but the maximum value of the tooth meshing frequency component $\left(f_{z}\right)$ for the each working pitch may be an effective evaluation index for the proposed simulation program. Note that not only tooth meshing frequency component $\left(f_{z}\right)$ but also $2 f_{z}$ and $3 f_{z}$ could be an effective evaluation index 
depending on the rotational speed of gears.

Next, the potential gear noises from different surface finishing methods were evaluated in concern to the noise characteristics. From the experiment results, it is reported that each gear noise has distinctive characteristics. The following expression is used to describe the characteristics of each potential gear noise. The participants have concluded that GTM and GTO gears tend to have low frequency sound compared to the others. The sound characteristic of GTO gear is perceived as smooth and fewer growls compared to GTM. GTR, THO and SV were categorized as having high frequency sound. In this way, the study participants feel the differences of the sound characteristics among the potential gear noises. It is confirmed that it is possible to perceive not only the difference of sound quality among SV gear and the ground gears but also the difference among the ground gears manufactured by different methods. Macroscopically, the tooth flank form of any ground gear looks the same and only small differences exist. However, it was found that, by using the proposed evaluation method, it is possible to distinguish clearly the sound characteristics caused by small differences of tooth flank form.

The uncomfortness of potential gear noises is evaluated and the result is shown in Fig. 9(b). Rank 1 means the most uncomfortable and rank 5 does the most comfortable. In the figure, each point represents the rank given by each study participant. In this result, the rank of GTO gear is concentrated at $4^{\text {th }}$ and $5^{\text {th }}$ and this reveals that the gear noise of GTO is recognized as more comfortable. Conversely, the rank of SV gear is concentrated at $1^{\text {st }}$ and $2^{\text {nd }}$ and this shows that the gear noise is considered as more uncomfortable. Considering the dispersion of rank of each gear is small, it can be concluded that the evaluation shows objective result to some extent. This suggests that the proposed evaluation method in terms of uncomfortness is valuable.

It is very difficult to experience and recognize the differences in sound quality and uncomfortness from the FFT of vibrational excitation (c.f. Fig. 7) results or the indices values (c.f. Fig.8) point of view. Therefore, from these experiments, it is considered that the sensory evaluation method using the potential gear noise is an effective means.

\section{Effect of Periodic Variation in Profile and Helix Slope Deviations}

In this section, the effect of periodic variation in profile and helix slope deviations among the teeth is investigated.

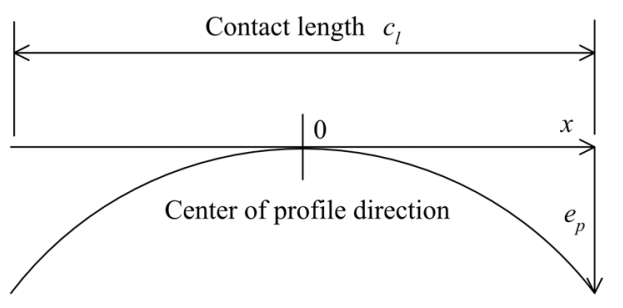

(a)

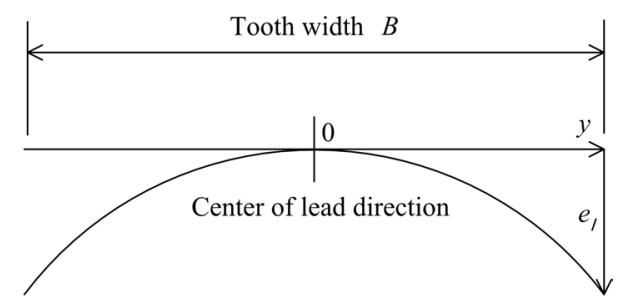

(b)

Fig. 10 Definition of rounded tooth flank form: (a) rounded tooth profile modification, and (b) rounded lead crowning modification

\subsection{Definition of Tooth Flank Form}

In the gear design, rounded tooth flank modification is generally given. In the present study, both the tooth profile and lead crowning modifications are taken into consideration. The rounded profile form (in the tooth height direction) is shown in Fig. 10(a). The geometry of the modification is given as follows:

$$
e_{p}(x)=e_{p} \cdot\left(\frac{|x|}{c_{l} / 2}\right)^{2}
$$


The lead crowning modification (in lead direction) is shown in Fig. 10(b). The form of the modification is expressed as follows:

$$
e_{l}(x)=e_{l} \cdot\left(\frac{|y|}{B / 2}\right)^{2}
$$

\subsection{Effects of Periodic Variation in Profile and Helix Slope Deviations}

In many cases, mass production gears have variations in profile slope deviation among the teeth. The primary cause of these variations is the eccentricity of the gear shaft. Under such a condition, the tooth profile slope deviation changes periodically. In this subsection, the effect of this variation is analyzed and discussed. Rounded profile modification of $5 \mu \mathrm{m}$ is performed for both sides of the drive and driven gears. As shown in Fig. 11, the profile slope deviation is assumed to change in a manner similar to a sine curve during one rotation of the gear. The mean value of profile slope deviation is set to $0 \mu \mathrm{m}$. In the analysis, the sine wave amplitude is changed from 2 to $14 \mu \mathrm{m}$ for both the drive and driven gears. The amplitude of change of $14 \mu \mathrm{m}$ corresponds to Grade 4 of ISO 1328-1:95 [14, 15]. A similar investigation is performed for a helix slope deviation, in which a rounded lead crowning modification of $5 \mu \mathrm{m}$ is performed.
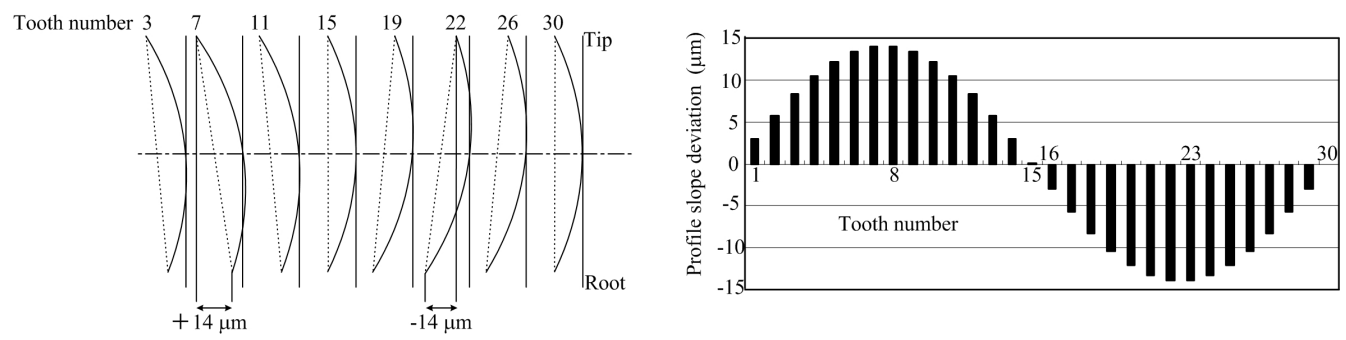

Fig. 11 Definition of periodic variation of profile slope deviation (The amplitude of variation of the profile slope deviation is $14 \mu \mathrm{m}$ in this example)
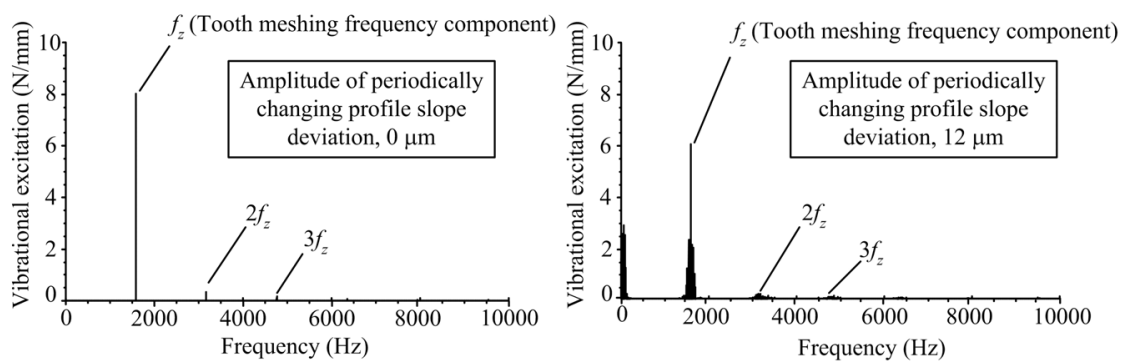

Fig. 12 FFT analysis of vibrational excitation under periodically changing profile slope deviation

The FFT analysis results under periodically changing profile slope deviation are shown in Fig. 12. The increase in amplitude of profile slope deviation reduces the peak value of the tooth meshing frequency component $\left(f_{z}\right)$, and, at the same time, the sideband frequencies near the meshing frequency components increase slightly. A similar tendency was also observed under the helix slope deviation.

The results of evaluation by the conventional index mentioned in Section 3.4 are shown in Fig. 13. The peak of the tooth meshing frequency component $\left(f_{z}\right)$ for overall working pitch decreases with the increase in variation of the profile or helix slope deviation, as indicated in Fig. 13(a). In contrast, in Fig. 13(b), the maximum amplitude of vibrational excitation for each working pitch and the maximum value of the tooth meshing frequency 
component $\left(f_{z}\right)$ increase gradually with the increase in variation of the profile or helix slope deviation.

The personal loudness level based on the potential gear noise is shown in Fig. 14. The participants reported that the potential gear noise made from the virtual tooth flank forms has the characteristics of actual gear noise, but it sounds like an electronic beeping sound as the variation in tooth flank form decreases. The result of the sensory evaluation shows a slight increase associated with the increase in variation of the profile or helix slope deviation. In other words, the result of the sensory evaluation is similar to the results obtained by the evaluation using the maximum amplitude of vibrational excitation for each working pitch, or its maximum value of the tooth meshing frequency component $\left(f_{z}\right)$ (see Fig. 13(b)). These results are identical to the results reported in Section 4. Based on the sensory evaluation results, when the profile or helix slope deviation changes periodically, the noise becomes slightly larger as the amount of variation increases. This analysis also shows that the evaluation based on the tooth meshing frequency component of vibrational excitation for the overall working pitch might has a opposite tendency compared to the evaluation based on the potential gear noise and thus, more attention should be paid for the evaluation index.

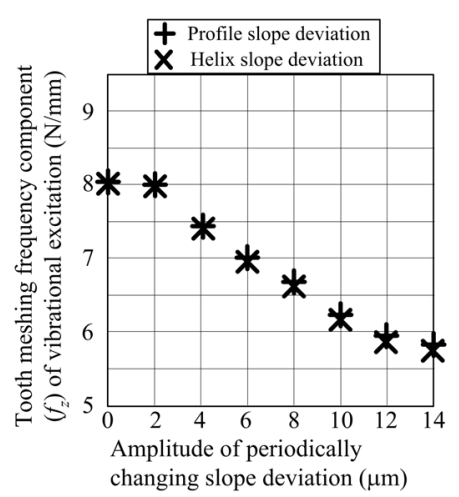

(a)

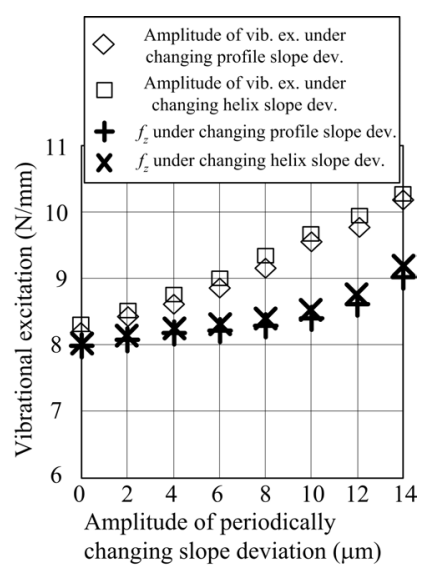

(b)

Fig. 13 Effects of periodically changing profile or helix slope deviation (a) on the tooth meshing frequency component of vibrational excitation for the overall working pitch, and (b) on the maximum amplitude of vibrational excitation and maximum value of tooth meshing frequency component for each working pitch

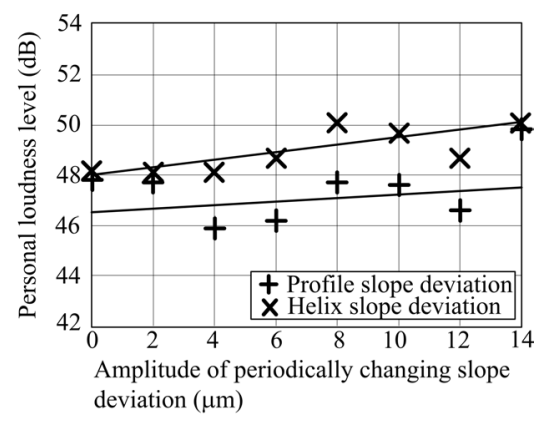

Fig. 14 Results of sensory evaluation under periodically changing profile or helix slope deviation

\section{Conclusion}

In this study, a simulation program was proposed in order to calculate the vibrational 
excitation under loading while considering the variations in the tooth flank form among the teeth of the gear and the small irregularity on the tooth flank. Using developed simulation program, the effect of surface finish method on the gear vibration and noise was analyzed. The effects of periodically changing profile and helix slope deviation among teeth on vibrational excitation were also investigated. In addition, the concept of potential gear noise, which is the noise obtained by converting the vibrational excitation into sound, and a sensory evaluation method based on the human auditory system were introduced in order to analyze directly the effect of tooth flank form on gear noise characteristics. The evaluation method in personal loudness level, noise quality and noise uncomfortness is proposed.

The results obtained in this study are summarized below:

1. Using the proposed simulation program, it is possible to evaluate the changes of tooth meshing condition among the meshing pairs of teeth of pinion and gear. In addition, the vibrational condition of gears can also be evaluated by the measured data of tooth flank form in submicrometer order.

2. The effect of the surface finish method on the vibrational performance can be assessed using the proposed program. The analysis of the effect of microscopic differences of the tooth flank form on the vibrational performance was made possible.

3. The sound which is generated from the conventional program does not have the sound characteristics of an actual gear noise and sounds like an electronic beep sound. On the contrary, the potential gear noise generated from the proposed program sounds like an actual gear noise. In addition, it is confirmed that the potential gear noise clearly exhibits differences in noise quality or characteristics among surface finish methods. Regarding ground gears, because each gear manufactured by different grinding method has almost identical tooth flank form macroscopically, sound level is almost the same for each gear. However, there is a large difference in the quality of gear noise among the grinding methods. For example, the uncomfortness of ground gear noise is clearly different among the grinding methods. From these results, it can be concluded that the proposed sensory evaluation method of potential gear noise could enable gear designers to experience directly the effect of tooth flank form on the noise quality and it is an effective means in the initial stage of gear design.

4. If the periodic variation in the profile or helix slope deviation increases, the tooth meshing frequency component $\left(f_{z}\right)$ for the overall working pitch decreases, whereas the sideband frequency increases. In contrast, the maximum amplitude of vibrational excitation for each working pitch and the maximum value of the tooth meshing frequency component $\left(f_{z}\right)$ increase gradually with the increase in variation of profile or helix slope deviation.

5. When comparing the index values of vibrational excitation to the personal loudness level of potential gear noise, the tooth meshing frequency component $\left(f_{z}\right)$ of vibrational excitation for the overall working pitch did not show a good correlation with the personal loudness level and, in many cases, they show the opposite trend. In contrast, the maximum amplitude of vibrational excitation or the maximum value of the tooth meshing frequency component $\left(f_{z}\right)$ for each working pitch shows a good correlation with the personal loudness level.

\section{Acknowledgment}

This study was supported by Industrial Technology Research Grant Program in 2009 from New Energy and Industrial Technology Development Organization (NEDO) of Japan.

\section{References}

(1) Ozguven, H. N., and Houser, D. R., 1988, "Mathematical Models used in Gear Dynamics - a Review,” J. Sound Vib., 121(3), pp. 383-411. 
(2) Velex, P., and Maatar, M. A., 1996 "Mathematical Model for Analyzing the Influence of Shape Deviations and Mounting Errors on Gear Dynamic Behavior," Journal of Sound and Vibration, 191(5), pp. 629-660.

(3) Blankenship, G. W., and Singh, R., 1992 “A Comparative Study of Selected Gear Mesh Force Interface Dynamics Models," Proceedings of the $6^{\text {th }}$ ASME International Power Transmission and Gearing Conference, Vol. DE-43-1, pp.137-146.

(4) Edzrol Niza Mohamad, Masaharu Komori, Hiroaki Murakami, Aizoh Kubo, and Suping Fang, 2009, "Analysis of General Characteristics of Transmission Error of Gears With Convex Modification of Tooth Flank Form Considering Elastic Deformation Under Load,” Journal of Mechanical Design, ASME J. Mech. Des., 131, DOI:10.1115/1.3116261.

(5) K. V. Froloz and O. I. Kosarev, 2003, "Control of Gear Vibrations at Their Source," J. Int. Applied Mechanics, 39-1, pp. 49-54

(6) Barthod, M., Hayne, B., Tebec, J.-L., Pin, J.-C., 2006 "Experimental study of dynamic and noise produced by a gearing excited by a multi-harmonic excitation," J. Applied Acoustics, 68, pp. 982-1002.

(7) Kurokawa, S., Ariura, Y., Nakanishi, T., 2007 "Transmission Error Analysis of Involute Cylindrical Gears with Consideration of Gear Eccentricity,” Bull. JSME 73(732), pp.2367-2374 (in Japanese)

(8) Kurokawa, S. and Ariura, Y., 2005 "Influence of Gear Eccentricity on the Characteristics of Noise Spectrum," JSME annual meeting 2005(4), pp.185-186 (in Japanese)

(9) Kubo, A., and Umezawa, A., 1976 " $1{ }^{\text {st }}$ Report on Study of Characteristics of Transmitted Load of Erroneous Cylindrical Gear,” Bull. JSME 43(371), pp.2771 (in Japanese)

(10)Komori, M., Kubo, A., Kawasaki, Y., 2000 "Design Method of Vibrationally Optimum Tooth Flank Form for Involute Helical Gears with Scattering in Pressure Angle and Helix Angle Deviation," Proceedings of DETC2000 ASME 8th International Power Transmission and Gearing Conference, Baltimore, DETC2000/PTG-14423.

(11)Komori, M., Kubo, A., Suzuki, Y., 2003, "Simultaneous Optimization of Tooth Flank Form of Involute Helical Gears in Terms of Both Vibration and Load Carrying Capacity," JSME International Journal (C), 46(4), pp.1572-1581

(12)Houjoh, H., Ratanasumawong, C., Matsumura, S., 2007, "Utilization of Synchronous Averaging for Inspection of Tooth Surface Undulations on Gears (Localization of Nonmesh Harmonic Components to Individual Gear)," Journal of Applied Mechanics, 74(2), pp. 269-278.

(13)Kubo, A., Nonaka, T., Kageyama, M., Kato, N., Kato, S., Ohmori, T., 1990, “Total Vibrational Excitation and Transmission Error of Gears as Index of Vibration and Noise of Power Transmissions," Bull. JSME, 56(532), pp.244-249

(14) Japanese Industrial Standard JIS B1702 Precision of spur gear and helical gear:1976

(15) Japanese Industrial Standard JIS B1702-1 Cylindrical gear-Accuracy Class-1998 (Corresponding to ISO 1328-1:95) 